$\begin{array}{ll} & \text { Etnográfica } \\ \text { etnográfica } & \text { Revista do Centro em Rede de Investigação em }\end{array}$

Antropologia

vol. $14(1) \mid 2010$

Vol. $14(1)$

\title{
Os dois países de Benjamim Pereira: uma homenagem
}

João Leal

\section{OpenEdition}

\section{Journals}

Edição electrónica

URL: https://journals.openedition.org/etnografica/364

DOI: 10.4000/etnografica.364

ISSN: 2182-2891

\section{Editora}

Centro em Rede de Investigação em Antropologia

\section{Edição impressa}

Data de publição: 1 fevereiro 2010

Paginação: 185-195

ISSN: 0873-6561

\section{Refêrencia eletrónica}

João Leal, «Os dois países de Benjamim Pereira: uma homenagem», Etnográfica [Online], vol. 14 (1)

2010, posto online no dia 18 outubro 2011, consultado o 11 fevereiro 2022. URL: http://

journals.openedition.org/etnografica/364 ; DOI: https://doi.org/10.4000/etnografica.364

\section{(c) (i) (8)}

Etnográfica is licensed under a Creative Commons Attribution-NonCommercial 4.0 International License. 


\title{
Os dois países de Benjamim Pereira: uma homenagem $^{1}$
}

\author{
João Leal
}

CRIA/FCSH-UNL

BENJAMIM PEREIRA VIVEU, PELO MENOS, EM DOIS PAÍSES. UM DELES era um país essencialmente rural. Era não só um país rural mas também um país diverso, de múltiplas ruralidades, que Benjamim Pereira tentou captar e cartografar. Era, finalmente, um país que foi retratado através de objectos, uns mais portáteis - alfaias agrícolas, máscaras -, outros não tanto - como é o caso das chamadas construções primitivas ou dos lagares de azeite. Foi nesse país que Benjamim Pereira habitou em grande parte do tempo que passou no Centro de Estudos de Etnologia e no Museu de Etnologia, e esse é um país para cujo conhecimento Benjamim Pereira deu uma contribuição muitíssimo relevante, cujos méritos seria fastidioso enumerar.

Mas Benjamim Pereira viveu - e felizmente vive ainda - noutro país. Um país que já não é rural sem que dele se possa dizer que é inteiramente urbano. Um país cuja diversidade é mais incerta e fracturante. Um país que se revê hesitantemente - ou que não se revê de todo - nos objectos que Benjamim Pereira coleccionou e estudou, um país do qual ainda não foram encontrados os objectos representativos.

Foi neste segundo país que Benjamim Pereira viveu nas últimas décadas. Participou nele de várias maneiras, das quais queria reter duas em particular. A primeira: Benjamim Pereira acompanhou, estimulou e foi interlocutor activo

l O presente texto reproduz, com ligeiríssimas alterações, a conferência que tive ocasião de proferir na sessão de abertura do IV Congresso da Associação Portuguesa de Antropologia (APA), que teve lugar em Lisboa entre 9 e 11 de Setembro de 2009. Agradeço à Catarina Alves Costa os comentários a uma versão preliminar do texto. 
de muitas das novas pesquisas que foram dando conta deste segundo país, desempenhando assim um papel único na passagem do testemunho geracional da antropologia portuguesa clássica para a antropologia portuguesa contemporânea. É a ele que devemos o privilégio de podermos sentir que nos inserimos numa genealogia disciplinar que é motivo de orgulho. A segunda: Benjamim Pereira foi ele próprio um investigador de aspectos importantes da reconversão pós-rural da sociedade portuguesa, como mostra, por exemplo, o livro Rituais de Inverno com Máscaras (2006), onde desafiou vários antropólogos mais jovens para com ele colaborarem num empreendimento onde tradição e invenção da tradição, velhas e novas máscaras vão a par. Mais recentemente, a sua pesquisa sobre o trajo à vianesa (Botelho, Medeiros e Pereira 2009) insere-se na mesma linha de trabalho de diálogo entre esses dois países em que Benjamim Pereira viveu (e ainda vive).

\section{O PRIMEIRO PAÍS}

Do primeiro país temos hoje, graças a Benjamim Pereira e aos seus companheiros do Centro de Estudos de Etnologia e do Museu de Etnologia, uma imagem de conjunto nítida, acabada, sólida. Nessa imagem avultam alguns grandes motivos estruturantes.

Era um país maioritariamente rural, que Benjamim Pereira nos restituiu por intermédio de dois registos principais. Um deles tem que ver com as condições materiais da vida rural. É a essa luz que pode ser entendida a importância que as alfaias agrícolas e os edifícios consagrados à produção agrícola têm na obra de Benjamim Pereira. O outro tem que ver com o universo do ritual. Um dos mais conhecidos - se não o mais conhecido - trabalho de Benjamim Pereira é o livro Máscaras Portuguesas (1973) - consagrado às Festas dos Rapazes e de Santo Estêvão em Trás-os-Montes -, e foi justamente a esse tema que Benjamim Pereira regressou recentemente com Rituais de Inverno com Máscaras.

O primeiro país era também um país diverso, de múltiplas ruralidades, que o trabalho de Benjamim Pereira contribuiu para cartografar. Dois registos são também aqui relevantes. Um deles tem que ver com o peso que na sua obra tem o modelo Portugal mediterrânico/Portugal atlântico/Portugal transmontano, proposto por Orlando Ribeiro (1963 [1945]) e operacionalizado antropologicamente por Jorge Dias. É esse modelo que está implícito em muitas das obras no domínio da cultura material que Benjamim Pereira escreveu com os seus colegas do Centro de Estudos de Etnologia. Simultaneamente, na sua obra podemos encontrar também uma atenção grande às desmultiplicações locais dessa diversidade tripartida, como mostra o seu trabalho sobre as máscaras de Trás-os-Montes, cuja distribuição coincide, para todos os efeitos, com uma microrregião no interior dessa região mais vasta constituída pelo Portugal transmontano. 
Era, finalmente, um país povoado de objectos. Objectos fotografados, recolhidos, cartografados, comprados, guardados, analisados minuciosamente (voltarei a este tema no final). O projecto antropológico de Benjamim Pereira e de toda a equipa de Jorge Dias era um projecto que, inserido numa tendência mais vasta da etnologia europeia do seu tempo, antecipava em larga medida o renovado interesse contemporâneo pela cultura material, ou pela "vida social das coisas", para citar uma formulação feliz de Appadurai (1986). Foi assim por intermédio de objectos - a partir de objectos - que Benjamim Pereira discursou as múltiplas ruralidades do primeiro país em que viveu.

\section{DO PRIMEIRO PARA O SEGUNDO PAÍS}

Hoje vivemos - e Benjamim Pereira também - num segundo país. Dele sabemos algumas coisas. Sabemos, por exemplo, que ele já não é rural, sem ser inteiramente urbano. É também um país diverso, embora diverso de outra forma. É um país com objectos - num certo sentido, é mesmo um país com cada vez mais objectos -, mas esses objectos são agora diferentes.

Deste segundo país, a nossa imagem é entretanto ainda fragmentada, incerta, incompleta.

Parte disso é um reflexo do espírito do tempo. Este é - como se sabe - um tempo de fragmentação do mundo e da antropologia. Um tempo avesso a sistematizações e onde a preferência vai para os "instantâneos" e para as vozes múltiplas. Um tempo - convertido à hibridez constitutiva da cultura - de que ninguém quer desenhar mapas com fronteiras nítidas e fixas. Este espírito do tempo é bem-vindo: vivemos no tempo em que vivemos e é a partir desse tempo e nos termos desse tempo que temos que pensar o mundo (e o país).

Mas outra parte da nossa incerteza actual tem a ver com a dificuldade em estabelecer diálogos produtivos entre pesquisas felizes que permanecem, infelizmente, fechadas em si próprias. A antropologia que se faz em Portugal e que toma a realidade portuguesa como objecto de estudo vive em larga medida uma contradição que não se tem revelado produtiva: nunca tanto se escreveu com tanta qualidade sobre contextos etnográficos tão diversificados e, ao mesmo tempo, nunca foram tão evidentes as dificuldades em usar essas etnografias na construção de uma teoria antropológica sobre o país. Cultivando o local, o estudo de caso, a observação intensiva de pequenas coisas, temos tido dificuldades em passarmos para escalas de análise mais abrangentes.

Nessa ausência, torna-se fácil a "teorias" essencializadoras sobre Portugal e os portugueses - baseadas em tropos como a inveja ou o mais recente "chico-espertismo" (Gil 2004, 2009) - fazerem um caminho triunfal, sem que encontrem qualquer oposição significativa na opinião publicada. 
Sucede que nada nos impede de tentar organizar de modo mais ambicioso o que temos vindo a conhecer sobre este segundo país. E, desse ponto de vista, o trabalho de Benjamim Pereira sobre o primeiro país propõe-nos pontos de partida produtivos.

\section{O SEGUNDO PAÍS: ENTRE O RURAL E O URBANO}

Em 1960, 40\% da população portuguesa era rural. Trinta anos depois, em 1991, o país estava reduzido a 10\% de rurais (Machado e Costa 1998). Acompanhando esta contracção demográfica significativa, no mesmo período o declínio do interior rural acentuou-se e - a par da emigração para a Europa e para a América - assistiu-se ao crescimento exponencial das cidades, em particular das grandes conurbações litorais que hoje concentram a maioria da população portuguesa.

Desta transformação central na natureza da sociedade portuguesa resultou um país muito menos rural, mais urbano e sobretudo mais suburbano. Mas sobre este segundo país continua, por enquanto, a pesar a sombra do primeiro, que Benjamim Pereira tão bem analisou.

É, em primeiro lugar, um país menos rural, mas onde a ruralidade, reconvertida em pós-ruralidade, mantém um peso significativo no imaginário social e político das populações e das elites, como mostram as discussões sobre a Política Agrícola Comum (PAC) ou a generalização de processos de emblematização da cultura popular de matriz rural, a que Benjamim Pereira tem sido tão sensível.

Sendo, em segundo lugar, um país mais urbano, é sobretudo um país mais suburbano, instavelmente situado entre o campo e a cidade. Por um lado, o êxodo rural traduziu-se no crescimento de uma larga e ininterrupta teia de subúrbios. Inversamente, no campo, as aldeias e as freguesias tornam-se cada vez mais arredores de redes regionais de cidades médias, às quais estão ligadas de diversas maneiras.

É, em terceiro lugar, um país - urbano e suburbano - marcado pelo crescimento das classes médias (incluindo as classes médias baixas), de 20\% em 1960 para quase 50\% em 1991 (Machado e Costa 1998).

É, finalmente, um país que deixou de caber em si próprio: o êxodo rural maciço começado nos anos 1960 alimentou uma persistente emigração para a Europa e para a América do Norte que, depois de um aparente abrandamento durante algumas décadas, voltou a atingir no século XXI números particularmente expressivos, embora persistentemente ignorados pelas elites políticas.

Como tem sido sublinhado, esta mutação estrutural do país foi rápida, foi muito rápida. Talvez por isso o segundo país só possa ser pensado - pelo menos por enquanto - a partir do primeiro, aquele cuja ruralidade Benjamim Pereira tão bem tematizou. 
Isso é particularmente evidente no que sobra do país rural reconvertido à pós-ruralidade ou no caso do país que emigrou. Este último em particular é um país pensado pelos seus protagonistas em torno de representações, embora imaginárias, da ruralidade.

Mas o pano de fundo da ruralidade é igualmente importante no estudo do país suburbano, um país para todos os efeitos instavelmente situado entre a cidade e o campo. O próprio crescimento das classes médias também não pode ser interpretado sem levar em linha de conta a ruralidade: uma parte significativa dessas novas classes médias - sobretudo das classes médias baixas - é uma classe média de primeira geração, de origens rurais mais ou menos frescas.

Este pano de fundo rural reflecte-se em numerosos fenómenos que antropólogos e sociólogos têm estudado. Explica a pluriactividade característica de muitas regiões do Norte do país. Dá conta das estratégias em relação ao desemprego em meio urbano, baseadas na "família-providência". Está na base de uma intensa mobilidade social, sem a qual não podemos explicar, por exemplo, o aumento da frequência - maioritariamente feminina - da universidade, mas também a sua paradoxal conjugação com altas taxas de insucesso escolar, resultantes da não correspondência entre aumentos do capital económico e aumentos de capital cultural. Subjaz à generalização de padrões de consumo assentes na combinação entre orçamentos de bens essenciais baixos - baseados no hipermercado - e compra a crédito de bens de prestígio de gama média ou média/alta - baseados no centro comercial.

Mas falta-nos ir mais longe. Não temos ainda o equivalente português de A Utopia Urbana de Gilberto Velho (2002 [1973]), aplicado a um prédio de apartamentos na Brandoa. Falta-nos também o equivalente ao filme Aquele Querido Mês de Agosto (de Miguel Gomes) sob a forma de uma monografia etnográfica.

E temos dificuldades em responder a questões relacionadas com a produção de novas formas culturais e de novos modelos de sociabilidade resultantes deste novo desenho do país. Qual a relação entre novas formas de cultura popular de massas - as novas feiras rurais, os arraiais animados por cantores "pimba" - e as reconfigurações suburbanas da ruralidade? Qual é a relação entre o país suburbano e a oferta religiosa das igrejas neopentecostais? Como explicar - em meio urbano e suburbano - a estranha mistura entre inovação social e tendências para a retradicionalização dos estilos de vida, evidentes na quase consensualização das praxes académicas ou no novo fôlego cerimonial de certos ritos de passagem? Qual a relação - se é que há alguma - entre os progressos da emancipação feminina no mundo pós-rural e a generalização do alterne? Que padrões de consumo são os dessas novas classes médias e que relações tecem com revindicações estatutárias? Que reivindicações estatutárias são essas? 


\section{O SEGUNDO PAÍS: NOVAS DIVERSIDADES E MOVIMENTO}

Situando-se em espaços intersticiais entre o urbano e o rural, Portugal é também um país que podemos interrogar a partir de preocupações - que eram as de Benjamim Pereira - acerca da sua diversidade. Editorialistas e comentadores políticos glosaram recentemente o tema da suposta homogeneidade de Portugal. Em certa medida - e de um ponto de vista comparativo - não deixa de ser verdade. Mas, a um outro nível, a afirmação tem que ser ponderada.

Como acabei de sugerir, há vários países - pós-rural, emigrante, suburbano, urbano - dentro do segundo país que é o de Benjamim Pereira e que também é o nosso. Simultaneamente, Portugal - embora em proporções menos importantes do que a grande maioria dos países europeus - é hoje um país que recebe imigrantes. Embora desigualmente distribuída pelo território, essa imigração acentuou a diversidade étnica, cultural e religiosa do país. É também um país que tem assistido à multiplicação de diferentes culturas juvenis, onde se combinam ligações transnacionais e formulações locais. As formas de organização familiar também se diversificaram, pondo em evidência a gradual crise de modelos morais de inspiração conservadora. Os seus subúrbios não são exactamente os mesmos e a sua população é heterogénea. É também, naquilo que nele continua a ser rural, um país de múltiplas ruralidades, embora diferentes das de Benjamim Pereira.

Uma grande parte da produção antropológica recente sobre Portugal tem feito o levantamento de muitas dessas novas diversidades, com relevo para aquelas que derivam da imigração. Mas temos até agora tido dificuldades em ir além desse levantamento casuístico. Se o primeiro país - graças também a Benjamim Pereira - tinha um mapa nitidamente traçado da sua diversidade, no segundo estamos ainda um bocado perdidos. Sabemos que é diverso, mas não como é diverso.

É verdade que essa nova diversidade do país é mais difícil de pensar. Por um lado, nela rompeu-se o laço entre cultura e território que era tão importante no modelo clássico Portugal mediterrânico/Portugal atlântico/Portugal transmontano. É, nesse sentido, uma diversidade mais desamarrada e menos dependente de constrangimentos geográficos. É também uma diversidade menos geométrica, ou, se quiserem, menos cartográfica. É uma diversidade feita de sobreposições, de justaposições, de fracturas. Mas é uma diversidade sem a qual se torna difícil entender o país. Estando em crise a diversidade que Benjamim Pereira assumiu na sua obra, o desafio que ela nos coloca é o de construirmos um modelo - ou modelos - alternativo(s).

Esse modelo poderia, por exemplo, ser pensado com recurso ao leit motif do movimento. O movimento que desde os anos 1960 conduziu uma população maioritariamente rural do campo para a cidade e os movimentos de mobilidade social a ela associados. O movimento dos imigrantes que chegaram, 
que ficaram ou que simplesmente utilizam Portugal como placa giratória para percursos transnacionais mais abrangentes. Mas também o movimento dos emigrantes, com particular relevo para os mais recentes, ainda largamente por cartografar. O movimento que conduziu a uma inserção cada vez mais efectiva do país em redes transnacionais e globais de circulação de pessoas, de mercadorias, de ideologias e de formas culturais que repercutem de forma distinta sobre diferentes grupos sociais. A diversidade do país seria neste caso descrita por intermédio de trajectos e de itinerários e dos sulcos e traços que estes deixam.

A estes movimentos de grande alcance ter-se-ia de acrescentar outros movimentos de menor latitude: do bairro de lata para o conjunto de habitação social; as viagens pendulares dos citadinos aos campos; o trânsito institucional das pessoas nas malhas do Estado; os movimentos pendulares masculinos do interior rural do Norte e Centro para a construção civil espanhola, com regresso aos fins-de-semana.

Como se sabe, desde a adesão de Portugal à União Europeia, o país é marcado: por novas facilidades de comunicação induzidas pelo aumento exponencial do parque automóvel e pelo crescimento, se possível ainda mais exponencial, dos equipamentos rodoviários, das auto-estradas às rotundas. Quais são os novos e velhos movimentos propiciados por essas novas facilidades de comunicação? Para onde vão esses carros todos? Que mundos diversos - ou não - é que eles ligam entre si?

Uma diversidade deste tipo seria também uma diversidade pensada não apenas a partir do movimento, mas dos impedimentos ao movimento. Como a barreira da raça que impede o exercício do direito à assimilação e condena à prisão étnica. Ou a mobilidade social descendente provocada pela deslocalização da produção industrial. Ou a generalização de uma condição juvenil precária que mina o projecto modernista da ascensão social contínua intergeracional.

Em qualquer caso, tanto o movimento como os impedimentos ao movimento deveriam ser olhados como fonte de energia social e cultural, de produção - voluntária ou forçada - de novas formas culturais e sociais: desde a associação étnica às novas festas de aldeia, dos grupos de auto-ajuda às coreografias políticas do protesto, das reconfigurações das formas familiares à emergência de novos sentidos de comunidade.

\section{OBJECTOS: MINÚCIA E HISTÓRIA}

Seja qual for a teoria antropológica sobre o segundo país que venhamos a construir, nela a obra de Benjamim Pereira pode servir-nos, por fim, de inspiração metodológica. Chego assim ao terceiro aspecto da antropologia de Benjamim Pereira: é uma antropologia construída a partir de objectos.

Os objectos - como é sabido - voltaram à agenda da antropologia. Marcada por uma revisão em profundidade das antinomias sobre as quais foi construída 
a sua versão modernista - entre natureza e cultura, entre sujeitos e objectos, entre mercadoria e dádiva -, a antropologia que se seguiu ao modernismo - que convive melhor, felizmente, com as ambivalências (Bauman 2007 [1991]) - é uma antropologia interessada pela vida social dos objectos. Num certo sentido, esses objectos são diferentes daqueles de que Benjamim Pereira falou: estão situados não do lado da produção, mas do lado da fruição e do consumo; não são objectos artesanais mas objectos que, embora apropriados individualmente, são produzidos em série. Dito isto, os novos estudos de cultura material têm tudo a ganhar com uma releitura atenta dos "velhos" estudos de cultura material e os trabalhos de Benjamim Pereira são, a esse respeito, incontornáveis.

Não é tanto desse ponto que gostaria de falar, mas mais do modo como o trabalho etnográfico que Benjamim Pereira desenvolveu com esses "velhos" objectos marcou uma maneira de fazer etnografia que pode continuar a ser inspiradora, mesmo que não trabalhemos sobre objectos (velhos ou novos). Há nela dois aspectos que são decisivos. A minúcia e a história. Os objectos de Benjamim Pereira eram, por um lado, objectos minuciosos. E eram, por outro lado, objectos com história.

Comecemos pela minúcia. Há um romancista francês, Georges Perec, ${ }^{2}$ que - entre outras características - povoa os seus romances de circunstanciadas descrições das paisagens físicas em que se movem os seus personagens: uma parede, a sua cor, o estado da pintura, as manchas de humidade, as infiltrações de água no canto superior direito, as gravuras nas paredes, o conteúdo detalhado do que cada uma delas contém; depois, as outras paredes, descritas com o mesmo cuidado; e assim sucessivamente: as mesas, o número de pernas, a cor da madeira, o seu toque, os riscos no tampo, as cadeiras uma a uma, a pequena mesinha num dos cantos onde repousa um copo, etc.

O trabalho de Benjamim Pereira com os objectos tem a mesma minúcia descritiva, como é evidente, por exemplo, num dos mais importantes livros de que foi co-autor: as Construções Primitivas em Portugal, escrito em colaboração com Ernesto Veiga de Oliveira e Fernando Galhano (Oliveira, Galhano e Pereira 1988 [1969]). O livro é uma descrição comovida de várias construções - cabanas de pescadores, abrigos pastoris, barcos de avieiros - que têm na precariedade o seu denominador comum. E aquilo que nele avulta - como de resto noutros livros de Benjamim Pereira - é essa minúcia descritiva que faz com que o livro possa ser hoje utilizado como uma espécie de manual de autoconstrução de um abrigo em pedra ou de uma cabana na praia.

Gostaria de dar um exemplo extraído da descrição de uma cabana de pescadores do Algarve: 
[...] a cabana começa a revestir-se a partir do fundo das paredes. A primeira fiada é colocada com o couce para baixo, ligeiramente mergulhada num rego aberto na areia, e disposta em pequenas manadas seguidas, encostadas a quatro ripas, e cosidas a ponto à terceira ripa a contar de baixo, ou, noutros casos, à primeira, igualmente a partir de baixo. As fiadas seguintes, nas paredes e na cobertura, são dispostas com o couce para cima, batendo-se previamente cada manada no solo ou sobre a perna, obliquamente, de modo a que os couces acertem perfeitamente em bisel, disfarçando assim os degraus das fiadas, no interior das cabanas (Oliveira, Galhano e Pereira 1988 [1969]: 195-196).

Para quem julgue que isto é apenas antropologia das técnicas - que também é -, vale a pena lembrar uma outra passagem do mesmo livro, ainda sobre as mesmas cabanas:

O arranjo interior destas cabanas é extremamente cuidado. As divisórias são geralmente recobertas por capas de revistas com vedetas cinematográficas, calendários, cartazes publicitários, fotografias, etc. A pobreza e o incaracterístico do mobiliário são atenuados pela disposição de toalhas e panos bordados, quadros com retratos de família e outros, jarras de flores, etc. (Oliveira, Galhano e Pereira 1988 [1969]: 198).

Ora bem: esta minúcia reencontra-se um pouco por toda a obra de Benjamim Pereira e dos seus colegas do Museu de Etnologia e do Centro de Estudos de Etnologia Portuguesa. Os seus objectos são minuciosos. E são também objectos com história. Essa história é em muitos casos uma história difusionista de longa duração que temos frequentemente dificuldade em subscrever. Nas Construções Primitivas, por exemplo, os abrigos pastoris em pedra recobertos a colmo das montanhas do Norte de Portugal são vistos como sobrevivências das habitações castrejas. Mas é também, em muitos casos, uma história de mais curta duração, documentalmente apoiada e que é uma história fundamental para a localização histórica de modos de vida que não são intemporais. Seja como for, construções primitivas ou lagares de azeite, máscaras transmontanas ou sistemas de serração de madeira, os objectos de que Benjamim Pereira nos fala são objectos com história.

Podemos falar sobre os diferentes contextos etnográficos em que trabalhamos sem necessariamente recorrer a objectos, embora possamos dizer - invertendo a formulação de Appadurai (1986) - que não são só os objectos que têm vida social, mas também a vida social que está ela toda cheia de objectos.

Mas sucede que (1) a minúcia permanece a melhor arma do nosso trabalho de etnógrafos. É a minúcia que colocamos na reconstituição de uma história de vida ou na descrição de um serviço religioso, no acompanhamento de uma 
reunião de activistas ou na observação etnográfica de uma consulta médica num bairro social, que nos permite seguir as injunções de James Clifford acerca do valor da etnografia na interpretação crítica do mundo contemporâneo: "not so fast!", "what else is there?" (Clifford 2000). A minúcia é o modus operandi da etnografia, que procede por esmiuçamento. E (2) desse esmiuçamento faz parte a história. A etnografia modernista, segundo Michel-Rolph Trouillot (2003), obedecia ao modelo "um observador/um tempo/um espaço". Hoje em dia, com a multiplicação dos trabalhos de campo multissituados, são já muitos os antropólogos que articulam entre si vários espaços. Comparativamente, o processo de efectiva inclusão dos vários tempos na pesquisa etnográfica está mais atrasado. Nascida de um projecto anti-historicista, a antropologia modernista criou uma barreira mais efectiva à história, tornando assim mais difícil a localização dos seus objectos no tempo. Entretanto - como sabemos -, cada objecto de investigação é necessariamente um objecto onde se sedimentam múltiplas camadas históricas, que têm de ser também elas esmiuçadas, de forma convincente e esclarecedora. Com Benjamim Pereira, para além da minúcia, podemos reaprender esse gosto - que deriva da necessidade - pela história e pelo seu esmiuçamento.

\section{ELOGIO DO BENJAMIM (COM PALMAS)}

Por estas razões todas, o Benjamim pode continuar a ajudar-nos na tarefa de responder aos desafios interpretativos do segundo país onde nós e ele vivemos. Por estas razões todas - que são já muitas - e por mais duas. Pela sua muito grande, pela sua enorme capacidade de partilhar saber e entusiasmo. Mas, sobretudo, pela sua disponibilidade sempre renovada para estimular sucessivas gerações de antropólogos a fazer aquilo de que eles gostavam e gostam. Sem preconceitos nem pré-condições. Sem reservas. Apenas pelo gosto de ver as pessoas fazerem bem as coisas que gostavam - e gostam - de fazer. Apenas pelo gosto de poder juntar aos seus retratos do primeiro (e do segundo) país, os nossos retratos do segundo país. Essa capacidade de partilha e de entrega é muito rara. É ela que distingue alguém que verdadeiramente se apaixona pelo mundo que verdadeiramente quer compreender. É também ela que faz do Benjamim uma pessoa única.

Por todas estas razões e por mais estas duas, temos todos uma dívida de gratidão para com o Benjamim, que estas e outras homenagens nunca poderão saldar totalmente. Peço por isso uma enorme, uma prolongada salva de palmas para o Benjamim! 


\section{REFERÊNCIAS}

APPADURAI, Arjun (org.), 1986, The Social Life of Things: Commodities in Cultural Perspective, Cambridge, Cambridge University Press.

BAUMAN, Zygmunt, 2007 [1991], Modernidade e Ambivalência, Lisboa, Relógio d'Água.

BOTELHO, João, António MEDEIROS, e Benjamim PEREIRA, 2009, Uma Imagem da Nação:

Traje à Vianesa, Viana do Castelo, Câmara Municipal de Viana do Castelo.

CLIFFORD, James, 2000, "Taking identity politics seriously: "the contradictory, stony ground...”, em P. Gilroy, L. Grosberg e M. McRobbie (orgs.), Without Guarantees: Essays in Honour of Stuart Hall, Londres e Nova Iorque, Verso, 94-1 12.

GIL, José, 2004, Portugal Hoje: O Medo de Existir. Lisboa, Relógio D’Água.

—, 2009, Em Busca da Identidade: O Desnorte. Lisboa, Relógio D’Água.

MACHADO, Fernando Luís, e António Firmino da COSTA, 1998, "Processos de Uma Modernidade Inacabada”, em J. M. Viegas e A.F. da Costa (orgs.), Portugal, Que Modernidade?, Oeiras, Celta, 17-44.

OLIVEIRA, Ernesto Veiga de, Fernando GALHANO, e Benjamim PEREIRA, 1988 [1969], Construções Primitivas em Portugal, Lisboa, Publicações Dom Quixote.

PEREC, Georges, 1989 [1975]. A Vida: Modo de Usar, Lisboa, Presença (tradução de Pedro Tamen).

PEREIRA, Benjamim, 1973, Máscaras Portuguesas, Lisboa, Junta de Investigações do Ultramar/Museu de Etnologia do Ultramar.

— (org.), 2006, Rituais de Inverno com Máscaras, Bragança, Museu do Abade de Baçal.

RIBEIRO, Orlando, 1963 [1945], Portugal, o Mediterrâneo e o Atlântico, Lisboa, Sá da Costa.

TROUILLOT, Michel-Rolph, 2003, Global Transformations: Anthropology of the Modern World, Nova Iorque, Palgrave.

VELHO, Gilberto, 2002 [1973], A Utopia Urbana: Um Estudo de Antropologia Social, Rio de Janeiro, Jorge Zahar Editor. 